\title{
Alterations in Low-Z Elements Distribution in Heart Tissue after Treatments to Breast Cancer Using LEXRF Technique
}

\author{
Andrea Mantuano ${ }^{*}$, Regina Cely Barroso' ${ }^{1}$ Liebert Parreiras Nogueira1, Marcos Vinicius Colaço1, \\ Carla Lemos Mota², Arissa Pickler², Delson Braz², Camila Salata ${ }^{3}$, Samara Ferreira-Machado 3 , \\ Carlos Eduardo de Almeida ${ }^{3}$, Alessandra Gianoncelli ${ }^{4}$
}

${ }^{1}$ Physics Institute, Rio de Janeiro State University, Rio de Janeiro, Brazil

${ }^{2}$ Nuclear Engineering Program, Federal University of Rio de Janeiro, Rio de Janeiro, Brazil

${ }^{3}$ Radiological Science Laboratory, State University of Rio de Janeiro, Rio de Janeiro, Brazil

${ }^{4}$ Elettra-Sincrotrone Trieste S.C.p.a., Trieste, Italy

Email: *mantuanoandrea@gmail.com

How to cite this paper: Mantuano, A., Barroso, R.C., Nogueira, L.P., Colaço, M.V., Mota, C.L., Pickler, A., Braz, D., Salata, C., Ferreira-Machado, S., de Almeida, C.E. and Gianoncelli, A. (2016) Alterations in Low-Z Elements Distribution in Heart Tissue after Treatments to Breast Cancer Using LEXRF Technique. American Journal of Analyticai Chemistry, 7, 754-771.

http://dx.doi.org/10.4236/ajac.2016.711068

Received: September 11, 2016

Accepted: October 28, 2016

Published: October 31, 2016

Copyright $\odot 2016$ by authors and Scientific Research Publishing Inc. This work is licensed under the Creative Commons Attribution International License (CC BY 4.0).

http://creativecommons.org/licenses/by/4.0/

\section{Abstract}

Data from Global Cancer Statistics show that breast cancer (BC) is the most common type of cancer among women, leading the number of deaths caused by cancer. The developments in diagnosis and treatment techniques for the BC, including chemotherapy and/or radiotherapy, increased the survival rates for this type of cancer. One late complication induced by BC treatment is the cardiotoxicity. This term comprises different cardiotoxic side effects, which include blood pressure alterations, myocardial ischemia, congestive heart failure and other damages. This study aimed to evaluate the cardiac alterations induced by radiotherapy and chemotherapy, simulating a treatment for BC in Wistar rats. It is, therefore, important to understand the mechanisms involved in the cardiotoxicity, in order to prevent women from this late effect, when they undergo BC treatments. The major interests in this work are in Low atomic weight elements as Sodium, because it is strongly related to cardiomyocyte contraction; Magnesium, because it is important in the cardiac metabolism; and Iron, because $\mathrm{BC}$ treatment induced cardiotoxicity can be associated to the oxidative stress. Changes that occur in unhealthy tissues in case to cardiovascular damages can be better understood when elemental compounds and structures of healthy tissues are known. Low Energy X-ray Fluorescence (LEXRF) technique was used to obtain elemental maps of low Z-elements providing a semi-quantitative analysis of the tissues evaluated under different conditions. Through the technique LEXRF we obtained elemental and absorption maps. The results showed more damages when associating chemotherapy and radiotherapy in comparison to myocardium healthy. Those images taken together with light microscopy, X-ray absorption and phase 
contrast images, satisfactorily characterize the cardiac tissue for the first time in the literature, from the structural and morphological points of view. LEXRF was carried out at TwinMic beamline in the ELETTRA Synchrotron Facility, at the beamline TwinMic, in Trieste, Italy.

\section{Keywords}

Micro-X-Ray Fluorescence, Low-Z Elements Distribution, Myocardial, Cardiac Tissue

\section{Introduction}

Soft X-rays can provide better contrast in absorption imaging than hard X-rays as a result of the high absorption cross sections of $\mathrm{C}, \mathrm{N}$ and $\mathrm{O} \mathrm{Ka}$ shells, the main organic matter constituents, in the soft X-ray regime [1].

A combination of compositional and morphological information can be used to make a semiquantitative investigation able to identify reliable marker elements and to better understand some aspects of healthy tissues and tissues treated with chemotherapy and/or radiotherapy [2] [3].

Several studies about cellular organization and caracterization are reported in literature. Le Gros, M.A., et al., 2012 [4] used soft X-ray tomography to visualize cells in three dimensions, obtaining remarkable images. However this technique does not allow identifying the elemental distribution.

X-ray fluorescence microprobe, X-ray Fluorescence Microscopy and Dynamic Contrast-enhanced MR Imaging, are used to establish elemental concentrations for a large number of different chemical elements simultaneously in different locations in cell and tissue samples [5]. Those techniques provide trace element sensitivity using hard Xrays, an opportunity to image whole cells and quantify high- $Z$ elements on a per cell basis.

SR- $\mu$ XRF (Synchrotron Radiation Micro X-Ray Fluorescence) maps are shown in the literature to investigate the elemental composition of different areas in the heart and other tissues. Lis, G. J., et al., 2014 [6] verified the distribution of calcium, phosphorus, strontium and zinc in calcified human aortic valves to prove topographical localization and colocalization of the examined elements by SR- $\mu$ XRF; Liang F., et al., 2010 [7] observed toxicological traces of injuries of rat's hippocampus by SR- $\mu \mathrm{XRF}$ and elemental mapping. Tatjana P., et al., 2006 [3] analyzed Cl, K, Ca, Ti, Mn, Fe, Cu, and $\mathrm{Zn}$ to observe changes that occur, for example, due to pathogenic diseases including cancer growth, and metals and metal chelators that represent an increasingly important class of drugs used to treat a diverse variety of diseases.

The highlight point in this work is the use of LEXRF that is a very specific and unique technique that allows mapping low- $Z$ elements [8] [9]. These analyses have not been done yet on for cardiac tissues. To analyze a tissue that suffers any Cardiovascular disease (CVD), it is important to know how low-Z elements of fundamental importance 
behave. CVD continues to be one of the main causes of death in the western world. A high burden of this disease and the high costs for the healthcare systems claim for novel therapeutic strategies besides current conventional medical care. The 2013 Global Burden of Disease Study estimated that almost 30\% of all deaths worldwide were caused by CVD [10] [11]. In 2012, in Europe, 46\% of CVD deaths were from coronary heart disease (CHD) and $26 \%$ were from stroke [12].

The CVD is not only associated to genetics and life quality of the patients, it can also be associated to some cancer treatments like radiotherapy and chemotherapy, but its effects depend on the agent used, on the patients age, and on previous history of cardiovascular diseases [13] [14]. Additionally, as cancer patients live longer, their risk of developing secondary cardiovascular events increases. The rapid development of novel cancer therapies will continue to generate questions of cardiac risk and cardiac protection in cancer patients over time [15] [16].

The determination of the distribution and chemical state of elemental constituents in biological systems at sub-cellular level down to trace level concentrations is becoming more and more important for getting new insights about the complex functions of elements in the tissue or the cell [8]. In this way, the study of low atomic weight elements distribution and its control image can help to understand a health tissue, their main elements, and consequently comprehend the mechanisms associated to any CVD due to structural changes in the cell, as they are of fundamental importance for metabolism in healthy biological systems.

Cardiac tissue is widely studied but little is known about the elements that become alternated with cardiac damage. It has already been used to characterize alterations associated to heart failure and apoptosis in CVD [17] [18].

It's well-known that different forms related to cardio toxicity caused by chemotherapeutic agents, including cellular damage caused by free radical formation, and induction of immunogenic reactions in the heart. The chemotherapy regimen choice depends on tumor stage, and also on the patient's clinical condition. One of the schemes used for $\mathrm{BC}$ treatment is the association of taxanes and cyclophosphamide, known as TC regimen. Taxanes such as docetaxel have been widely incorporated into the chemotherapy options for early stage $\mathrm{BC}$ treatment. The taxanes mechanism of action is the inhibition of cell division by interrupting the function of microtubules, but their use is also related to cardio toxicity, and the exact way this occurs is still unknown. Alkylating agents such as cyclophosphamide, act directly in the alkylation of the DNA molecule. The precise mechanisms of cyclophosphamide-induced cardiotoxicity are also unknown. One hypothesis is that cyclophosphamide causes direct damage to the endothelium followed by extravasations of toxic metabolites, resulting in damage to the cardiomyocytes, hemorrhage and edema [19]. Regarding radiotherapy treatment for BC using photons, it is known that the radiation-induced heart disease (RIHD) is a late effect caused by radiation in the thoracic region, when all or part of the heart is in the radiation field. Among the manifestations of RIHD are valvulopahy, pericarditis and myocardial fibrosis [20]. It is, therefore, important to understand the mechanisms involved in the cardio toxicity, in order to prevent women from this late effect, when they un- 
dergo $\mathrm{BC}$ treatments. When some structures of the tissue are damaged due to any drug or treatment, some elemental compounds can be modified.

This study is focused on the evaluation of low atomic weight elements' distribution to comprehend those mechanisms. The elements of major interest are: i) Iron (Fe), since $\mathrm{BC}$ treatment can induce decrease of capillary density at the tissue; ii) Magnesium $(\mathrm{Mg})$, because it is important in the cardiac metabolism and iii) Sodium ( $\mathrm{Na}$ ) that it is important for muscular contraction [21] [22].

This work aims to evaluate changes in low- $Z$ elements present in cardiac tissue sections of healthy Wistar rats to construct control images. These images using Low Energy X-Ray Fluorescence (LEXRF) were then used to compare tissues that suffered damage from chemotherapy and/or radiotherapy treatments.

\section{Materials and Methods}

\subsection{Animals}

Wistar rats $(\mathrm{n}=15), 3$ months old, were obtained from the Radiological Sciences Laboratory of State University of Rio de Janeiro, Brazil, and divided randomly into G0 control group; a G2 group receiving chemotherapy + irradiation (TC + IR), and a G3 group that received only irradiation (IR). The animals were kept in an appropriate environment on a $12 \mathrm{~h}$ light/dark cycle with free access to food and water, maintained under standard animal facility condition. Five animals were irradiated using a Varian Clinac linear accelerator, with a $6 \mathrm{MV}$ X-ray and dose rate of $240 \mathrm{cGy} / \mathrm{min}$ at the Clementino Fraga Filho University Hospital (HUCFF), Rio de Janeiro, Brazil. The irradiation on the heart area was performed in a single dose of $20 \mathrm{~Gy}$, and a field of $4 \mathrm{~cm}^{2}$. Chemotherapy was administered in 4 cycles in other five Wistar rats, with one week interval between them. The rats were euthanized 5 months after the end of treatments, (intraperitoneal ketamine/xylazine, $0.1 \mathrm{mg} / \mathrm{kg}$ ), sacrificed and their left ventricles were collected. The local committee for animal experimentation at the State University of Rio de Janeiro approved the experimental protocols (No. CEA/010/2012).

\subsection{Sample Preparation to Low-Energy X-Ray Fluorescence (LEXRF)}

The left ventricle (LV) fragments were placed in a freshly prepared formaldehyde (4\% $\mathrm{w} / \mathrm{v}$ ) in $0.1 \mathrm{M}$ phosphate buffer, $\mathrm{pH} 7.2$, for $48 \mathrm{~h}$ at room temperature, processed and then embedded in Paraplast plus (Sigma-Aldrich, St. Louis, MO, USA). Four LV fragments were included for each animal $5 \mu \mathrm{m}$ thick sections were obtained with an ultramicrotome and put on Ultralene film.

\subsection{Instrumentation of Low-Energy X-Ray Fluorescence (LEXRF)}

The experiment of LEXRF was performed at the TwinMic beamline [23] (Elettra Sincrotrone Trieste, Trieste, Italy), working in the $0.40-2.2 \mathrm{keV}$ energy range, allowing detection of the elements from boron to phosphorus and the L lines of some transition metals with submicron spatial resolution [24].

The beamline experimental station allows high resolution X-ray microscopy imaging 
coupled with low energy X-ray fluorescence (LEXRF) and, under specific condition, micro-XANES spectroscopies as well. For the current experiment TwinMic was operated in scanning mode, where the sample is raster scanned across a microprobe delivered by a zone plate diffractive optics.

The transmitted $\mathrm{X}$-rays provide absorption and differential phase contrast images constructed by the transmitted photons collected by using a fast readout CCD camera or a photodiode. The X-ray fluorescence photon emission, which provides elemental images and LEXRF microspot spectra, can be simultaneously detected by 8 silicon drift detectors (SDDs) with an active area of $30 \mathrm{~mm}^{2}$ and FWHM of $135 \mathrm{eV}$ at $5.9 \mathrm{keV}$ [24] [25]. The SDD axes are at 20 degrees in respect to the specimen surface $\mathrm{n}$ an annular configuration, and are around $28 \mathrm{~mm}$ distance from the focal point of the zone plate optics. The zone plate is objective lens with a resolution of $20-30 \mathrm{~nm}$. Figure 1 shows schematically the Twinmic STXM-LEXRF setup.

Heart tissue sections that were mounted on Ultralene foil fixed in teflon support were carefully examined with light microscope to select regions of interest (ROIs) with a $1.4 \mathrm{keV}$ of effective energy. LEXRF images were acquired with a $1.4 \mathrm{keV}$ of incident energy and with 25 seconds of exposure time per pixel with a field of view of at least $1600 \mu \mathrm{m}^{2}$ and spatial resolution of $1 \mu \mathrm{m}$.

For the present experiment the beam diameter, delivered by a $600 \mu \mathrm{m}$ diameter and $50 \mathrm{~nm}$ outermost zone $\mathrm{ZP}$, was about $1.2 \mu \mathrm{m}$. At each step the fluorescence radiation intensity was measured by the eight SDDs of the LEXRF setup. The X-ray fluorescence spectra were analyzed by PyMCA software [26], the maps were fitted and the X-rays intensities corrected by Compotn and Rayleigh intensity. Simultaneously, the transmitted intensity was measured by a fast-readout electron-multiplying low-noise chargecoupled device detector (FR-CCD) through an X-ray-visible light converting system (Figure 1).

Zone plate, sample, and SDDs were in vacuum, thus avoiding any absorption and scattering by air [8] [24] [27].

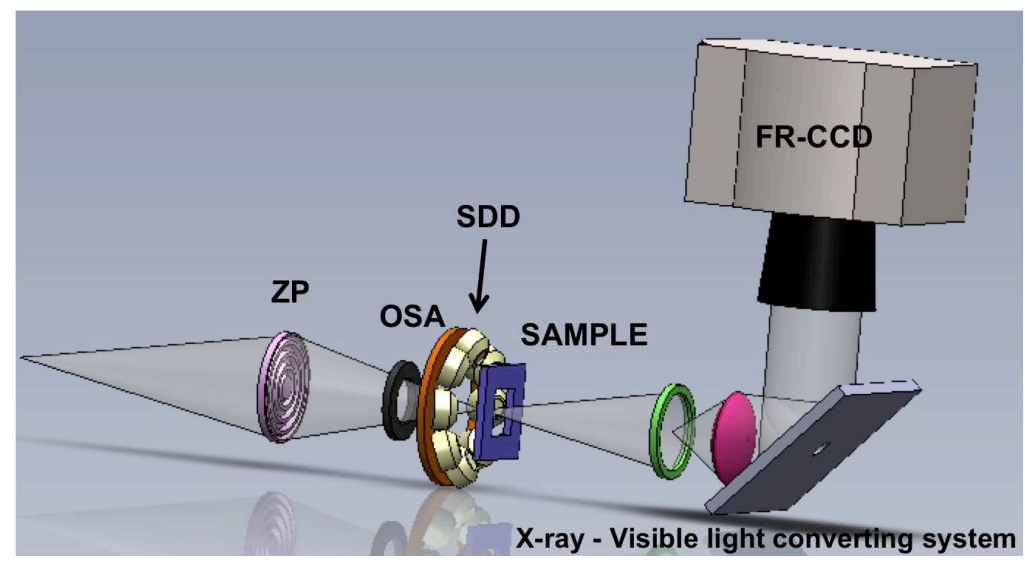

Figure 1. TwinMic setup: focusing system formed by condenser zone plates (ZP), an order-selecting aperture (OSA), 8 SDDs, and a fast readout CCD (FRCCD). 


\section{Results}

Images of light microscopy and LEXRF images were obtained for each group. All the images were analyzed, and typical images are showed in this section.

Figure 2(a) shows a light microscopy image of healthy cardiac tissue (G0), Figure 2(b) shows a light microscopy image of G2 group and Figure 2(c) shows a light microscopy image of G3 group, both with higher magnification $(100 \times)$. The circle indicates a blood vessel and the arrows indicate the cardiomyocyte nuclei that are the interesting in this work. The tissues were stained with picrosirius red, in order to better visualize the LV cardiac tissue. Red arrows indicate the cardiomyocyte nuclei.

Through this control image we can observe intact nuclei typical of a healthy tissue: nuclei, fibers and structures are well intact (therefore not destroyed). This image is comparative with the absorption and phase contrast images. On the other hand, treated groups images, Figure 2(b) and Figure 2(c), show disorganization of LV tissue, vacuolization of cytoplasm, and higher cardiomyocytes.

The LEXRF images were obtained for all the elements present in the sample and excited by $1.4 \mathrm{keV} \mathrm{X}$-ray photons. The tissue sections were exanimate by light microscopy to choose the best regions of interest to obtain the XRF maps. Typical spectra from the eight detectors are as shown in Figure 3. Each spectrum with different color represents one detector.

The spectra were analyzed by PyMCA. We used the sum spectra of the eight detectors to construct the first map, from this map we choose some pixels to do the fit and obtain the calibration spectrum. Figure 4 shows an example for a sum spectrum showing relative intensities of $\mathrm{C}, \mathrm{O}, \mathrm{Na}, \mathrm{Mg}$ and Compton peak in one spot of the map from G0 sample. This fit and calibration was done for each group.

Figure 5, Figure 6 and Figures 7(a)-(c) show XRF intensity maps $1600 \mu \mathrm{m}^{2}$ of Sodium, Magnesium and Iron for the G0, G2 and G3, groups respectively. All intensity maps were corrected by Compton and Rayleigh (scattering) intensities. The maps in Figures 5-7 depict representative areas for G0, G2 and G3 groups, respectively.

In this work, we choose to pay attention to $\mathrm{Na}, \mathrm{Mg}$ and $\mathrm{Fe}$ distribution due to their

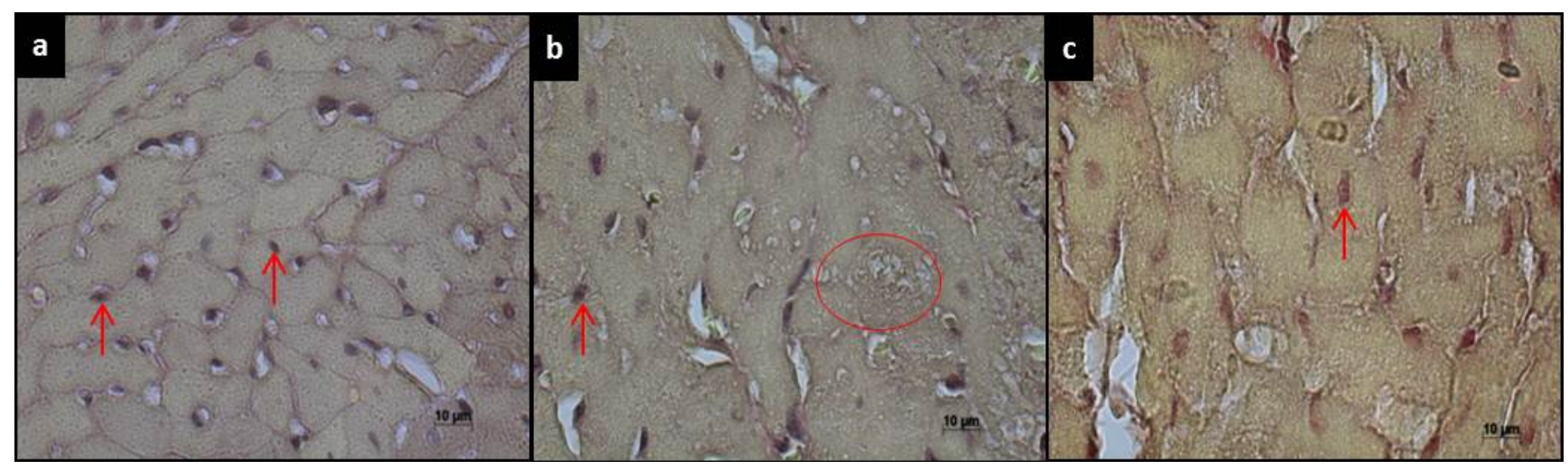

Figure 2. Light microscopy image, magnification of 100x, and stained with pricrosirius red: (a) control group; (b) G2 group (chemotherapy + irradiation); (c) G3 group (irradiation). Arrows indicate the cardiomyocyte nuclei. Circle indicates vacuolization. 


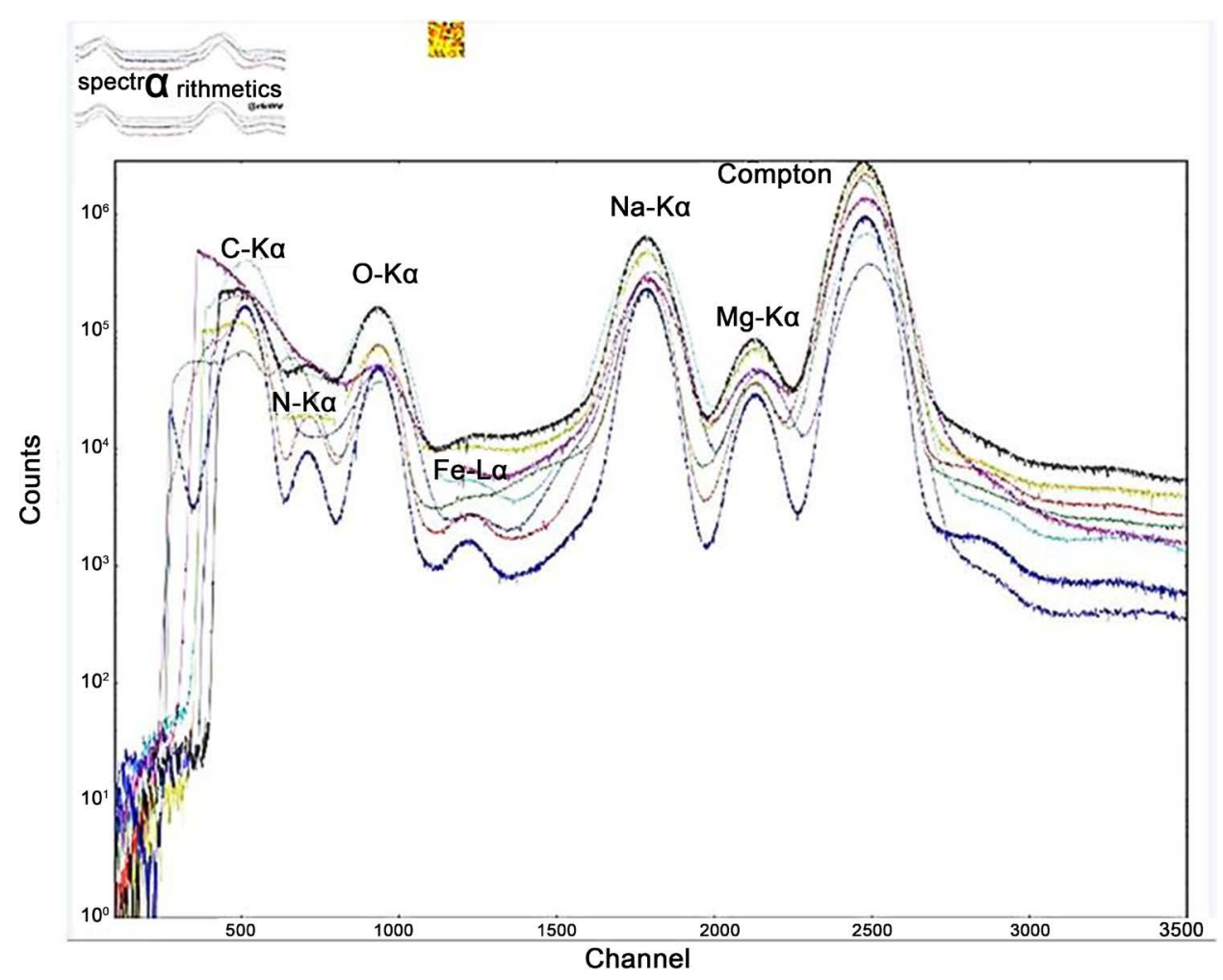

Figure 3. XRF spectra panel outlines the relative intensities of $\mathrm{C}, \mathrm{O}, \mathrm{Na}, \mathrm{Mg}$ and Compton peak for all eight detectors from TwinMic beam line.

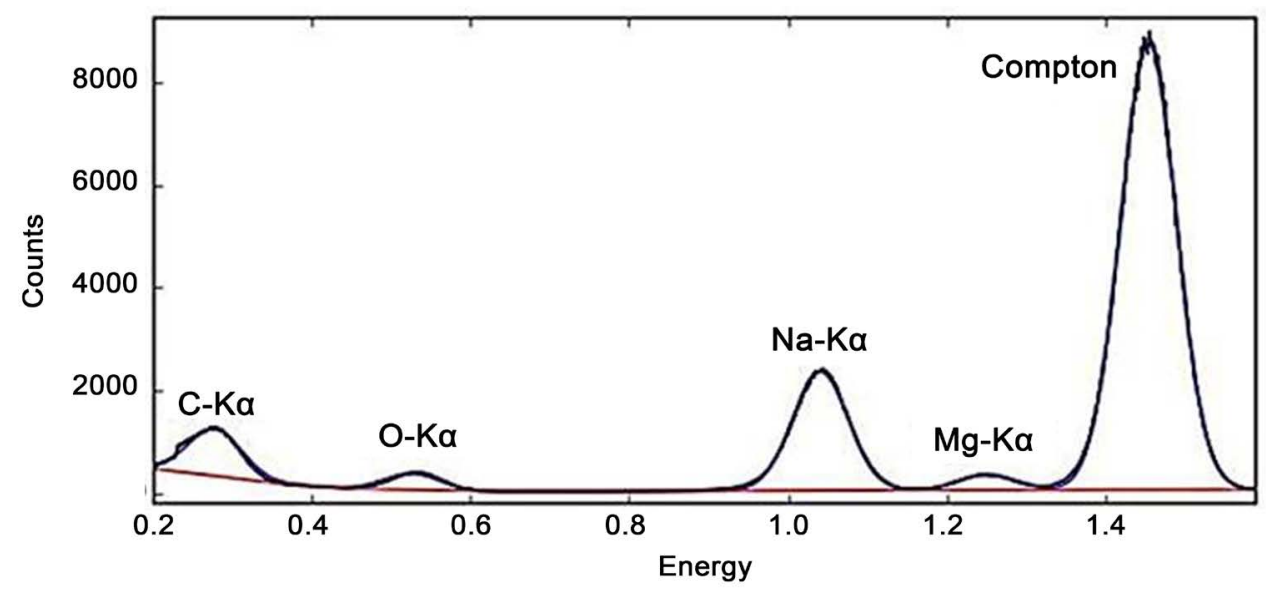

Figure 4. XRF spectra panel outlines the relative intensities of $\mathrm{C}, \mathrm{O}, \mathrm{Na}, \mathrm{Mg}$ and the scattered peak Compton.

major importance in the tissue physiology.

Figure 5, Figure 6 and Figure 7(d) and Figure 7(e) show absorption and phase contrast images, also in $1600 \mu \mathrm{m}^{2}$, respectively, corresponding to the analysed areas. All maps were fitted and analysed first with Pymca, normalized by the acquisition time and the scattering intensities to correct the effect of coherent and incoherent scattering. Afterwards they were ploted with Image J program to obtain the scale bars and color. They 


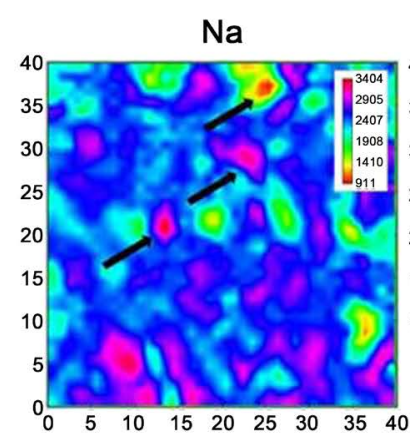

(a)

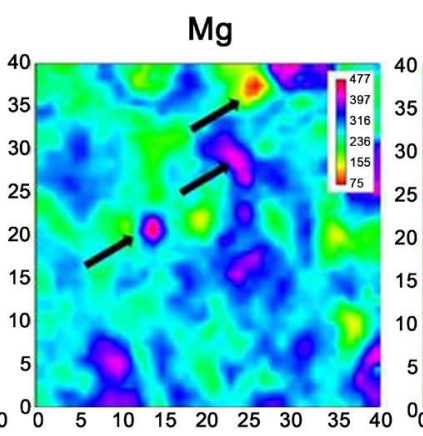

(b)
$\mathrm{Fe}$

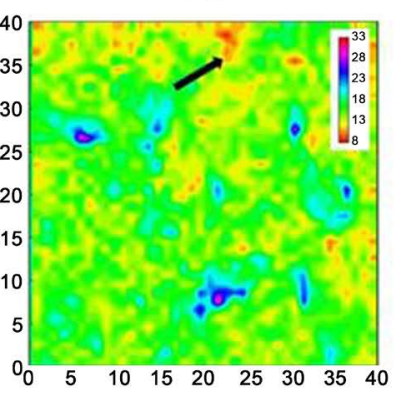

(c)

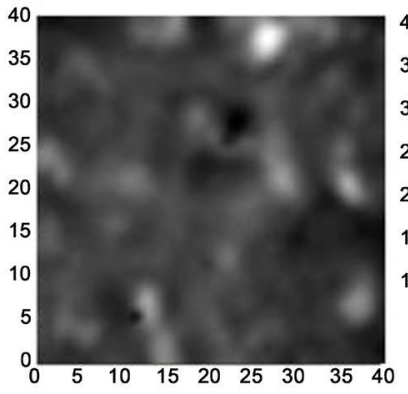

(d)

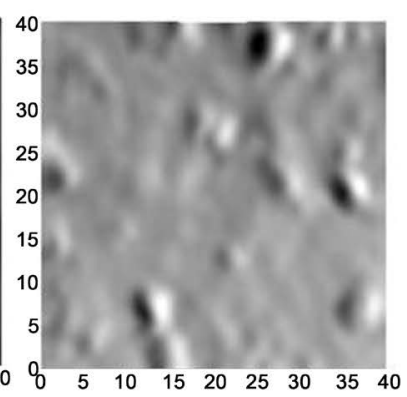

(e)

Figure 5. Intensity maps $1600 \mu \mathrm{m}^{2}$ acquired by LEXRF of G0 sample: (a) $\mathrm{Na}$, (b) $\mathrm{Mg}$ and (c) Fe. black arrows indicate the cardiomycyte nuclei. (d) and (e) represent the corresponding absorption and differential phase contrast images, respectively.

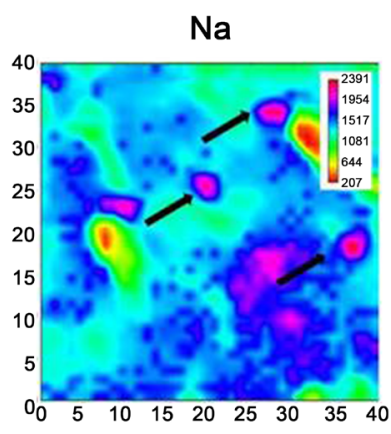

(a)

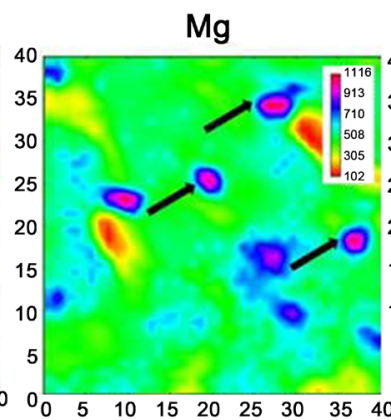

(b)

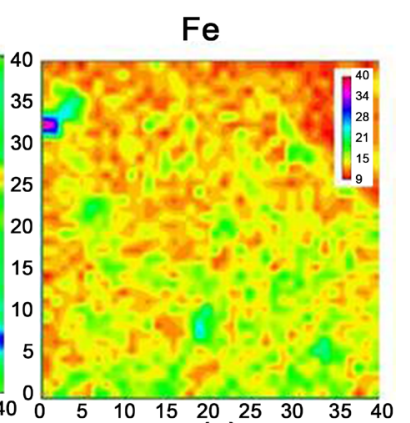

(c)

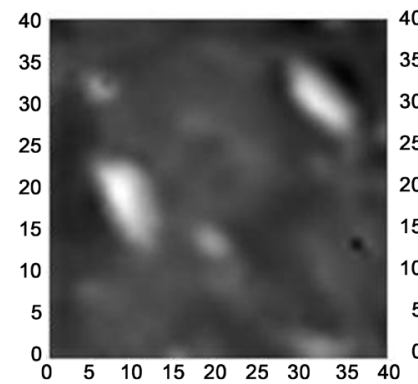

(d)

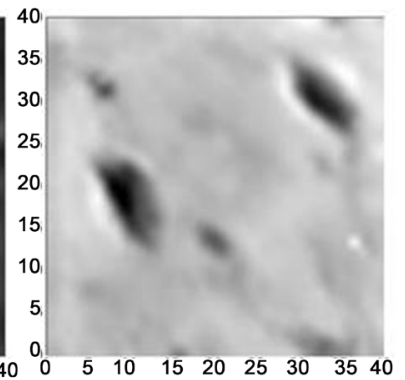

(e)

Figure 6. Intensity maps $1600 \mu \mathrm{m}^{2}$ acquired by LEXRF of G2 sample: (a) $\mathrm{Na}$, (b) $\mathrm{Mg}$ and (c) Fe. Black arrows indicate the cardiomycyte nuclei. (d) and (e) represent the corresponding absorption and differential phase contrast images, respectively. 


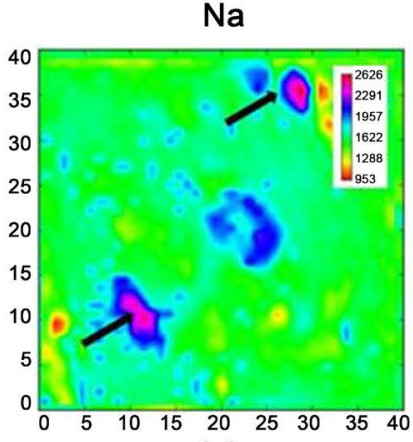

(a)

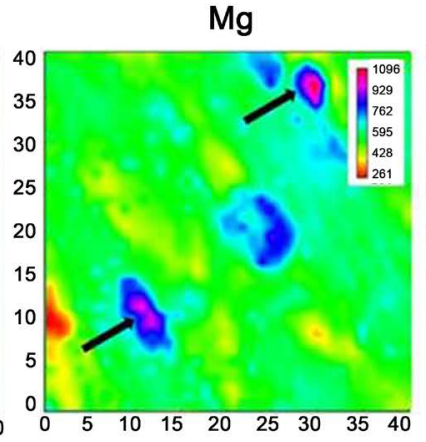

(b)
$\mathrm{Fe}$

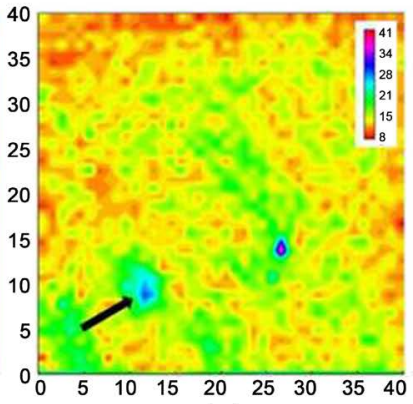

(c)

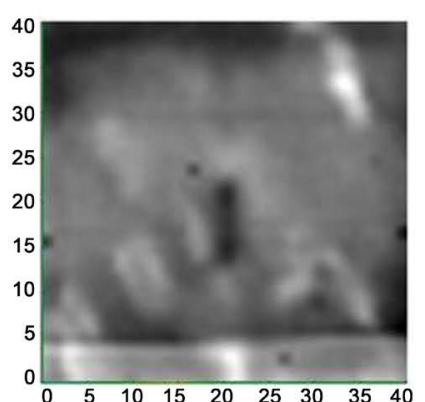

(d)

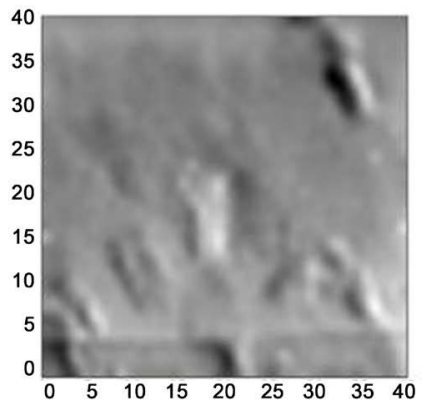

(e)

Figure 7. Intensity maps $1600 \mu \mathrm{m}^{2}$ acquired by LEXRF of G3 sample: (a) Na, (b) Mg and (c) Fe. black arrows indicate the cardiomycyte nuclei. (d) and (e) represent the corresponding absorption and differential phase contrast images, respectively.

provide a semiquantitative result, correlating the intensities to concentrations. All intensities were analyzed by ANOVA test and post test Tukey with a significative value of $\mathrm{P}<0.05$.

The contrast in the absorption images is due to changes in density/thickness in the sample, highlighting the most absorbing regions, while the phase contrast images mainly reveal the tissue structure Figure 5, Figure 6 and Figure 7(d) and Figure 7(e).

X-ray fluorescence images (Figures 5-7) of the cardiac tissue revealed the cytoplasm and cardiomyocyte nuclei (the nuclei are indicated by black arrows). The maps show the relative intensities for each important element corrected by scattering and their distribution in relation to different structures on the tissue. We can identify nuclei, cytoplasm and their elemental compounds.

Figures 8(a)-(c) show the averages of the intensities, based on the LEXRF measurements, for each group after the scattering correction.

The control images can be compared with the tissues that suffer damages. The results in the Figure 8 show that $\mathrm{Na}$ and $\mathrm{Mg}$ have an inverse behavior for G2 and G3 groups in comparison to G0. In G2 and G3 groups, Na intensity decreases significantly while $\mathrm{Mg}$ intensity increases with a significance of $\mathrm{p}<0.001$. This can be better observed on their average values. For Na, in G2, the intensity $\left(13.96 \times 10^{2} \pm 0.91 \times 10^{2}\right)$ decrease was higher than for G3 group $\left(16.18 \times 10^{2} \pm 0.34 \times 10^{2}\right)$ in comparison to control group G0 $\left(24.44 \times 10^{2} \pm 1.14 \times 10^{2}\right)$. This can be caused by the chemotherapy agents and must be considered after the breast cancer treatment $(\mathrm{p}<0.0001)$. 
$\mathrm{Na}$

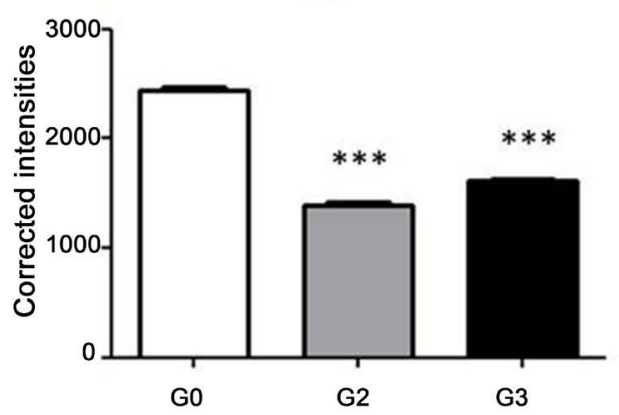

(a)

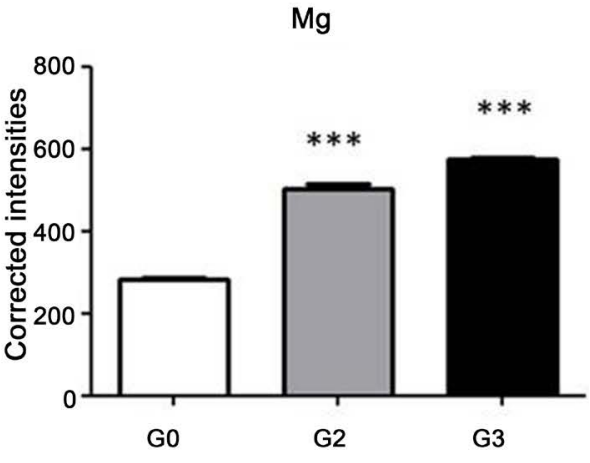

(b)

$\mathrm{Fe}$

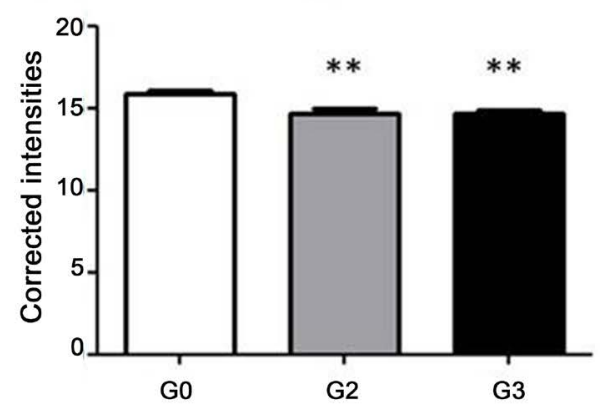

(c)

Figure 8. Average of corrected intensities by Compton and Rayleigh scattering, obtained with the LEXRF technique of (a) G0 group, (b) G2 and (c) G3. Symbol ${ }^{* * *}$ means significant difference (p $<0.0001)$ versus control group. Symbol ${ }^{* *}$ means significant difference $(\mathrm{p}<0.01)$ versus control group. Values are given as mean \pm standard error.

It is possible to observe in the whole LV tissue, for both nuclei and cytoplasm, that the Mg average intensity was higher for G2 $\left(5.04 \times 10^{2} \pm 0.36 \times 10^{2}\right)$ and G3 $\left(5.74 \times 10^{2}\right.$ $\left.\pm 0.23 \times 10^{2}\right)$ than in control group $\left(2.84 \times 10^{2} \pm 0.15 \times 10^{2}\right)$ with a significant value of $\mathrm{p}$ $<0.0001$ (Figure 8(a) and Figure 8(b)).

Fe showed a significant difference for G2 group $\left(0.14 \times 10^{2} \pm 1.03\right)$ receiving chemotherapy + irradiation and G3 group $\left(0.14 \times 10^{2} \pm 1.05\right)$ in comparison to control group $\left(0.15 \times 10^{2} \pm 0.78\right)$ with $\mathrm{p}<0.01$.

\section{Discussion}

The main purpose of the present study was to use two different image techniques to better characterize the LV cardiac tissue, elementary and morphologically, using an animal model with Wistar Rats. Basically, Low-Energy X-ray fluorescence (LEXRF) that allowed transmitted X-rays providing absorption and phase contrast images, were used to compare healthy cardiac tissues and cardiac tissues after chemotherapy and/or radiotherapy.

The X-ray fluorescence technique was used to obtain distribution maps of important light elements for both healthy and cardiac damaged tissues. The maps were obtained 
for different elements, but we chose three elements of great importance for the cardiac health: $\mathrm{Na}, \mathrm{Mg}$ and Fe. By determining the elemental distribution in healthy tissue, we can evaluate the possible damages and relate them to structural changes [28] [29] [30] [31]. Elemental maps can be correlated to the absorption and phase contrast images that provide information on specimen morphology, in order to identify the elemental changes that cause any structural damage. The perfect functioning of the heart depends on the cardiomyocytes contraction, which directly depends on sodium. Severe damage to heart, such as ischemia-myocardial infarction, has been associated with apoptosis of cardiomyocyte. Myocardial ischemia, changes cell metabolism to anaerobic respiration, resulting in intracellular sodium overload [32]. The changes we observed on $\mathrm{Na}$ intensity can be better observed in the maximum values in the nuclei area.

Mitochondria are the major source of energy in cardiac muscle tissue. These organelles generate ATP from metabolites through oxidative phosphorylation. Degradation in mitochondrial structure was correlated with substantial and persistent elevation in resting cytosolic sodium levels [33]. The LEXRF images show that sodium is more concentrated in the nucleus of the cardiomyocytes. Previous studies observed that the physiological stretch of the cardiac muscle increases the concentration of sodium and calcium in the nucleus of the cardiac cells using the technique electron probe microanalysis (EPMA) [34].

The choice of Magnesium was based on its essential physiological and biochemical importance in cellular processes, on the regulation of the cardiovascular function. $\mathrm{Mg}$ plays a critical role in modulating vascular smooth muscle tone, endothelial cell function, and myocardial excitability and is thus central to the etiopathology of several cardiovascular disorders, including hypertension, atherosclerosis, coronary artery disease, congestive heart failure, and cardiac arrhythmias [35]. The XRF maps of Mg shows a distribution similar to Na: both of them are almost not present in the cytoplasm.

Previous studies using chemical analysis and hormonal simulation showed that within cells, magnesium is compartmentalized in the nuclei, mitochondria, and endo/ sarcoplasmic reticulum. Within these compartments, magnesium binds to chromatin and nucleic acid, matrix adeninephosphonucleotides and intermembrane proteins, and ribonuclear proteins and phospholipids, respectively [36] [37]. In the heart, it is certainly recognized that hypomagnesemia is associated with a variety of arrhythmias in clinical and experimental studies [38]. Myocardium, reduced Mg levels could represent a common link between these adverse cardiovascular events. Several recent studies also demonstrated an association of low serum $\mathrm{Mg}$ level and increased risk of atrial fibrillation and sudden cardiac death using a mathematical model of a cardiac ventricular myocyte [39] [40].

In this study we found an increased intensity of $\mathrm{Mg}$, both in nuclei and cytoplasm, after radiotherapy and/or chemotherapy administration. It seems to be contradictory, based on the fact that lower levels of $\mathrm{Mg}$ were associated to cardio toxicity. Nevertheless previous studies about the doxorubicin cardiotoxic effects also reported an increase of Mg levels after chemotherapy administration [41] [42]. Doxorubicin a widely chemo- 
therapeutic agent, used for $\mathrm{BC}$, and other types of cancer treatment. The most accepted hypothesis is that $\mathrm{Mg}$ could be useful in protecting myocardial cells against doxorubicin induced injury, and it is possible that the cell requirement of $\mathrm{Mg}$ increases during the administration of doxorubicin, to counterbalance the toxic effects of the drugs

In general, some chemical elements describe different behavior on the cytoplasm and on the nuclei. Some studies in the literature showed that Magnesium is the fourth most abundant cation in the human body and the second most abundant in the intracellular space. $\mathrm{Na}$ and $\mathrm{Mg}$ are associated with different problems in the cardiac tissue as relationship between hypomagnesemia and cardiovascular disease [43] [44] showing their importance to maintain the tissue healthy. $\mathrm{Na}$ intensities are lower in the nuclei when the tissue suffer chemo and radiotherapy treatment and when suffer only radiotherapy. For $\mathrm{Mg}$ the beahaviour is the opposite: there is an increase in intensity.

The average intensities of $\mathrm{Na}$ and $\mathrm{Mg}$ on the nuclei are higher than in the cytoplasm [45] [46] [47] (Figures 5-7).

Another important element that was analysed in this study was Iron. It was observed an increase in iron uptake into the cardiomyocyte nuclei after radiotherapy and/or chemotherapy. In fact, iron is essential for a wide range of vital cellular functions such as oxygen transport, energy production, and cell division. But it is also known that excessive iron leads to generation of oxidative stress by increasing production of reactive oxygen species (ROS). Of the different organs, the heart is particularly vulnerable to iron toxicity [48]. All the cell types that constitute the heart may be susceptible to ROS-induced damage, including endothelial cells and the cardiomyocytes. Iron's toxicity within cells arises from its capacity to catalyse the production of ROS that cause lipid peroxidation and organelle damage, which leads to cell death and fibrosis and ultimately impaired systolic and diastolic function [49] [50].

Previous studies analysed the association between iron overload and the cardiotoxicity induced by doxorubicin. It has been suggested that DOX induces an iron mediated increase in ROS, referred to as the "ROS and iron hypothesis". According to this hypothesis, in the presence of iron, DOX leads to futile redox cycling, inducing substantial ROS production and cellular damage [51] [52] [42]. Ichikawa et al. (2014) [53] show that the cardiotoxicity of DOX occurs through preferential accumulation of iron specifically in the mitochondria and that a reversal in mitochondrial iron accumulation alleviates the deleterious effects of DOX on the heart. As the precise mechanism of the cardiotoxicity induced by irradiation and TC treatment remains unclear, the iron uptake into cardiomyocyte nuclei observed in this present study can help to better understand those mechanisms.

Although the XRF images can be used to show the distribution of chemical elements, it's not possible to use those images to clearly interpret morphological and structural changes on the tissue, only to identify from intensities. Morphological and structural changes can however be identified by light microcopy. In Figure 2 in order to better visualize the cardiac tissue, the sections were stained allowing highlighting the cells' nuclei and the cytoplasm. In the Figure 2(a) we could observe that the LV tissue was 
intact, the cells were organized, and no fibrosis was identified. This is corroborated by other studies that compare the cardiac tissue of healthy animals with the same tissue of animals treated with cardiotoxic drugs by clinical exams [31].

Those are characteristcs of healthy cardiac tissue, as shown in the literature by echocardiography, electron microscopy, diffusion tensor (DT) and Magnetic Resonance (MR) images acquired ex vivo [54] [55]. Cardiotoxic agents causes alterations in this pattern, including disorganization of myofibrils and mitochondria, vacuolization of the cytoplasm, and degeneration of crista inside the mitochondria [56] that we could observe on the Figure 2(b) and Figure 2(c).

We can note that previous studies cited in this work did not use any image technique to obtain low- $Z$ elemental and structural information about the health tissue although, it is important to know how some elements are distributed to study any problem on the cardiac tissue. Indeed LEXRF technique is also able to identify and locate the elements taking into account a semi-quantitative analysis and colocalization.

\section{Conclusions}

The present study shows an important technique to characterize the LV cardiac tissue, their elemental compounds and distribution. There are no previous studies in the literature using LEXRF images to study the cardiac tissue. The combination of X-ray imaging (absorption and phase contrast) with elemental semi-quantitative analysis has provided new insights into the biological events occurring at submicron scale.

Through light microscopy images, we observed some changes on the structure of cardiac tissue induced by irradiation and chemotherapy. Using LEXRF technique we obtained the distribution maps and an elemental analysis of low- $Z$ elements present in the sample in a semi-quantitative way, localizing the structures that changed, all of this corroborated with light microscopy images. In this study, we focused on elements that play an important role in the cardiac function: $\mathrm{Na}, \mathrm{Mg}$ and Fe. Those maps can help to better understand the mechanisms involved in the perfect functioning of the heart, identifying the elements and their intensities in the structure of the nucleus and cytoplasm. Those images taken together with light microscopy, X-ray absorption and phase contrast images, can satisfactorily characterize the cardiac tissue, from the structural and morphological points of view.

In this first study we showed that cardiovascular alterations are caused by different agents, like a simulated radiotherapy and chemotherapy causing important elemental alterations. For example, the LEXRF maps show a decrease in $\mathrm{Na}$ and $\mathrm{Fe}$ intensities, and an increase in the relative $\mathrm{Mg}$ intensity in comparison to control group. The disorganization of nuclei, fibers and some structures observed by light microscopy images corroborates with these elemental changes. The treatment for G2 group receiving chemotherapy + irradiation was shown more aggressive since Na reduces its intensity and $\mathrm{Mg}$ increases its intensities more than for G3 (group that received only radiotherapy) in comparison to G0 (control group) with a significative difference of $\mathrm{p}<0.0001$.

This work provides the possibility to know if there is an excess or a lack of some im- 
portant elements on the tissues and helps to localize some changes through the maps obtained by LEXRF. It opens a new point of view to do a control of these elements for a good functioning of the heart. This control can avoid cardiac diseases, infarct and other problems that can be fatal immediately or in a long term. It is important to know that all elements analyzed in this work are low- $Z$ elements which are essential to a healthy heart tissue. The results showed a high sensibility and precision and can open new insights to the Physics and to the Biology.

\section{Acknowledgements}

The authors acknowledge Lucia Merolle and Lorella Pascolo for helpful discussions involved in acquisition and interpretation of results, the financial support by Brazilian Government organizations CAPES, the organization within the Brazilian Ministry of Science and Technology CNPq, and the Elettra Synchrotron Facility, in Trieste, Italy, where LEXRF was carried out by the project TwinMic 20145302. We are also immensely grateful to Thiago Souza and Patricia Reis for their help on the sample preparation at Immunopharmacology Laboratory, IOC/FIOCRUZ, RJ, Brazil.

\section{References}

[1] Attwood, D. (2007) Soft X-Rays and Extreme Ultraviolet Radiation: Principles and Applications. Cambridge University Press, Cambridge.

[2] Jansen, S.A., Paunesku, T., Fan, X., et al. (2009) Ductal Carcinoma in Situ: X-Ray Fluorescence Microscopy and Dynamic Contrast-Enhanced MR Imaging Reveals Gadolinium Uptake within Neoplastic Mammary Ducts in a Murine Model 1. Radiology, 253, 399-406. http://dx.doi.org/10.1148/radiol.2533082026

[3] Paunesku, T., Vogt, S., Maser, J., Lai, B. and Woloschak, G. (2006) X-Ray Fluorescence Microprobe Imaging in Biology and Medicine. Journal of Cellular Biochemistry, 99, 14891502. http://dx.doi.org/10.1002/jcb.21047

[4] Le Gros, M.A., et al. (2012) Visualizing Sub-Cellular Organization Using Soft X-Ray Tomography. In: Edward, H.E., Ed., Comprehensive Biophysics, Elsevier, Amsterdam, 90-110. http://dx.doi.org/10.1016/B978-0-12-374920-8.00212-5

[5] Swaminathan, S., High, W.A., Ranville, J., Horn, T.D., Hiatt, K., Thomas, M. and Shah, S.V. (2008) Cardiac and Vascular Metal Deposition with High Mortality in Nephrogenic Systemic Fibrosis. Kidney International, 73, 1413-1418. http://dx.doi.org/10.1038/ki.2008.76

[6] Lis, G.J., Czapla-Masztafiak, J., Kwiatek, W.M., et al. (2014) Distribution of Selected Elements in Calcific Human Aortic Valves Studied by Microscopy Combined with SR- $\mu$ XRF: Influence of Lipids on Progression of Calcification. Micron, 67, 141-148. http://dx.doi.org/10.1016/j.micron.2014.08.002

[7] Liang, F., Zhang, G., Xiao, X., Cai, Z., Lai, B., Hwu, Y. and Zhang, C. (2010) Toxicological Study of Injuries of Rat's Hippocampus after Lead Poisoning by Synchrotron Microradiography and Elemental Mapping. Nuclear Instruments and Methods in Physics Research Section B: Beam Interactions with Materials and Atoms, 268, 2840-2845.

http://dx.doi.org/10.1016/j.nimb.2010.07.001

[8] Kaulich, B., Gianoncelli, A., Beran, A., Eichert, D., Kreft, I., Pongrac, P. and Kiskinova, M. (2009) Low-Energy X-Ray Fluorescence Microscopy Opening New Opportunities for BioRelated Research. Journal of the Royal Society interface, 6, S641-S647. 
http://dx.doi.org/10.1098/rsif.2009.0157.focus

[9] Hosthor, S.S., Mahesh, P., Priya, S.M., Sharada, P., Jyotsna, M. and Chitra, S. (2014) Quantitative Analysis of Serum Levels of Trace Elements in Patients with Oral Submucous Fibrosis and Oral Squamous Cell Carcinoma: A Randomized Cross-Sectional Study. Journal of Oral and Maxillofacial Pathology, 18, 46. http://dx.doi.org/10.4103/0973-029X.131902

[10] Hirt, M.N., Hansen, A. and Eschenhagen, T. (2014) Cardiac Tissue Engineering State of the Art. Circulation Research, 114, 354-367. http://dx.doi.org/10.1161/CIRCRESAHA.114.300522

[11] Naghavi, M., Wang, H., Lozano, R., Davis, A., Liang, X., Zhou, M. and Aziz, M.I.A. (2015) Global, Regional, and National Age-Sex Specific All-Cause and Cause-Specific Mortality for 240 Causes of Death, 1990-2013: A Systematic Analysis for the Global Burden of Disease Study 2013. Lancet, 385, 117-171. http://dx.doi.org/10.1016/S0140-6736(14)61682-2

[12] Bhatnagar, P., Wickramasinghe, K., Williams, J., Rayner, M. and Townsend, N. (2015). The Epidemiology of Cardiovascular Disease in the UK 2014. Heart, 101, 1182-1189. http://dx.doi.org/10.1136/heartjnl-2015-307516

[13] Albini, A., Pennesi, G., Donatelli, F., Cammarota, R., De Flora, S. and Noonan, D.M. (2010) Cardiotoxicity of Anticancer Drugs: The Need for Cardio-Oncology and Cardio-Oncological Prevention. Journal of the National Cancer Institute, 102, 14-25. http://dx.doi.org/10.1093/jnci/djp440

[14] Harris, J.R., Gebauer, W., Söhngen, S.M., Nermut, M.V. and Markl, J. (1997) Keyhole Limpet Hemocyanin (KLH), II: Characteristic Reassociation Properties of Purified KLH1 and KLH2. Micron, 28, 43-56. http://dx.doi.org/10.1016/S0968-4328(97)00011-5

[15] Petek, B.J., Greenman, C., Herrmann, J., Ewer, M.S. and Jones, R.L. (2015) Cardio-Oncology: An Ongoing Evolution. Future Oncology, 11, 2059-2066.

http://dx.doi.org/10.2217/fon.15.89

[16] Lee, A.M., Beaudoin, J., Engel, L.C., et al. (2013) Assessment of Image Quality and Radiation Dose of Prospectively ECG-Triggered Adaptive Dual-Source Coronary Computed Tomography Angiography (cCTA) with Arrhythmia Rejection Algorithm in Systole versus diastole: A Retrospective Cohort Study. The International Journal of Cardiovascular Imaging, 29, 1361-1370. http://dx.doi.org/10.1007/s10554-013-0208-8

[17] Treskatsch, S., Shakibaei, M., Feldheiser, A., et al. (2015). Ultrastructural Changes Associated with Myocardial Apoptosis, in Failing Rat Hearts Induced by Volume Overload. International Journal of Cardiology, 197, 327-332.

[18] Saito, T., Asai, K., Sato, S., Takano, H., Mizuno, K. and Shimizu, W. (2014) Ultrastructural Features of Cardiomyocytes in Dilated Cardiomyopathy with Initially Decompensated Heart Failure as a Predictor of Prognosis. European Heart Journal, 36, 724-732. http://dx.doi.org/10.1093/eurheartj/ehu404

[19] Yeh, E.T. and Bickford, C.L. (2009) Cardiovascular Complications of Cancer Therapy: Incidence, Pathogenesis, Diagnosis, and Management. Journal of the American College of Cardiology, 53, 2231-2247. http://dx.doi.org/10.1093/eurheartj/ehu404

[20] Boerma, M. and Hauer-Jensen, M. (2010) Preclinical Research into Basic Mechanisms of Radiation-Induced Heart Disease. Cardiology Research and Practice, 1-8.

[21] Ganga, H.V., Noyes, A., White, C.M. and Kluger, J. (2013) Magnesium Adjunctive Therapy in Atrial Arrhythmias. Pacing and Clinical Electrophysiology, 36, 1308-1318. http://dx.doi.org/10.1111/pace.12189

[22] Xu, Z. and Zhou, J. (2013) Zinc and Myocardial Ischemia/Reperfusion Injury. Biometals, 26, 863-878. http://dx.doi.org/10.1007/s10534-013-9671-x 
[23] Kaulich, B., Bacescu, D., Susini, J., et al. (2006) TwinMic: A European Twin X-Ray Microscopy Station Commissioned at ELETTRA. 8th International Conference on X-Ray Microscopy, Himeji, 26-30 July 2005, 22-25.

[24] Gianoncelli, A., Kourousias, G., Stolfa, A. and Kaulich, B. (2013) Recent Developments at the TwinMic Beamline at ELETTRA: An 8 SDD Detector Setup for Low Energy X-Ray Fluorescence. Journal of Physics: Conference Series, 425, Article ID: 182001.

http://dx.doi.org/10.1088/1742-6596/425/18/182001

[25] Gianoncelli, A., Kaulich, B., Alberti, R., et al. (2009) Simultaneous Soft X-Ray Transmission and Emission Microscopy. Nuclear Instruments and Methods in Physics Research Section $A, 608,195-198$. http://dx.doi.org/10.1016/j.nima.2009.06.035

[26] Solé, V.A., Papillon, E., Cotte, M., Walter, P. and Susini, J. (2007) A Multiplatform Code for the Analysis of Energy-Dispersive X-Ray Fluorescence Spectra. Spectrochimica Acta Part B: Atomic Spectroscopy, 62, 63-68. http://dx.doi.org/10.1016/j.sab.2006.12.002

[27] Malucelli, E., Iotti, S., Gianoncelli, A., et al. (2014) Quantitative Chemical Imaging of the Intracellular Spatial Distribution of Fundamental Elements and Light Metals in Single Cells. Analytical Chemistry, 86, 5108-5115. http://dx.doi.org/10.1021/ac5008909

[28] Gaur, N., McDonald, W., Hool, L. and Rudy, Y. (2009) Contributions of Ion Currents to Action Potential Changes and Induction of Early after Depolarizations and Sustained Triggered Activity during Acute Hypoxia in Ventricular Myocytes. Heart Rhythm, 6, 1691. http://dx.doi.org/10.1016/j.hrthm.2009.09.048

[29] Shen, Y., Dong, W., Feig, B.W., Ravdin, P., Theriault, R.L. and Giordano, S.H. (2009) Patterns of Treatment for Early Stage Breast Cancers at the MD Anderson Cancer Center from 1997 to 2004. Cancer, 115, 2041-2051. http://dx.doi.org/10.1002/cncr.24271

[30] Salata, C., Ferreira-Machado, S.C., De Andrade, C.B.V., Mencalha, A.L., Mandarim-DeLacerda, C.A. and de Almeida, C.E. (2014) Apoptosis Induction of Cardiomyocytes and Subsequent Fibrosis after Irradiation and Neoadjuvant Chemotherapy. International Journal of Radiation Biology, 90, 284-290. http://dx.doi.org/10.3109/09553002.2014.887869

[31] Boerma, M. and Hauer-Jensen, M. (2010) Preclinical Research into Basic Mechanisms of Radiation-Induced Heart Disease. Cardiology Research and Practice, 2011, Article ID: 858262.

[32] Hong, S., Lee, J., Seo, H.H., Lee, C.Y., Yoo, K.J., Kim, S. M., Choi, E., et al. (2015) $\mathrm{Na}^{+}-\mathrm{Ca}^{2+}$ Exchanger Targeting miR-132 Prevents Apoptosis of Cardiomyocytes under Hypoxic Condition by Suppressing $\mathrm{Ca}^{2+}$ Overload. Biochemical and Biophysical Research Communications, 460, 931-937. http://dx.doi.org/10.1016/j.bbrc.2015.03.129

[33] Kyrychenko, V., Poláková, E., Janíček, R. and Shirokova, N. (2015) Mitochondrial Dysfunctions during Progression of Dystrophic Cardiomyopathy. Cell Calcium, 58, 186-195. http://dx.doi.org/10.1016/j.ceca.2015.04.006

[34] Wilhelm, J., Kondratev, D., Christ, A. and Gallitelli, M.F. (2006) Stretch Induced Accumulation of Total $\mathrm{Ca}$ and $\mathrm{Na}$ in Cytosol and Nucleus: A Comparison between Cardiac Trabeculae and Isolated Myocytes. Canadian Journal of Physiology and Pharmacology, 84, 487-498. http://dx.doi.org/10.1139/y05-134

[35] Kolte, D., Vijayaraghavan, K., Khera, S., Sica, D.A. and Frishman, W.H. (2014) Role of Magnesium in Cardiovascular Diseases. Cardiology in Review, 22, 182-192. http://dx.doi.org/10.1097/CRD.0000000000000003

[36] Romani, A., Marfella, C. and Scarpa, A. (1992) Cell Magnesium Transport and Homeostasis: Role of Intracellular Compartments. Mineral and Electrolyte Metabolism, 19, 282-289.

[37] Romani, A. (2007) Regulation of Magnesium Homeostasis and Transport in Mammalian 
Cells. Archives of Biochemistry and Biophysics, 458, 90-102.

http://dx.doi.org/10.1016/j.abb.2006.07.012

[38] Shimaoka, T., Wang, Y., Morishima, M., Miyamoto, S. and Ono, K. (2015) Hypomagnesemic Down-Regulation of L-Type $\mathrm{Ca}^{2+}$ Channel in Cardiomyocyte as an Arrhythmogenic Substrate in Rats. Pathophysiology, 22, 87-93.

http://dx.doi.org/10.1016/j.pathophys.2015.01.002

[39] Ishihara, K., Sarai, N., Asakura, K., Noma, A. and Matsuoka, S. (2009) Role of $\mathrm{Mg}^{2+}$ Block of the Inward Rectifier $\mathrm{K}^{+}$Current in Cardiac Repolarization Reserve: A Quantitative Simulation. Journal of Molecular and Cellular Cardiology, 47, 76-84.

http://dx.doi.org/10.1016/j.yjmcc.2009.03.008

[40] Peacock, J.M., Ohira, T., Post, W., Sotoodehnia, N., Rosamond, W. and Folsom, A.R. (2010) Serum Magnesium and Risk of Sudden Cardiac Death in the Atherosclerosis Risk in Communities (ARIC) Study. American Heart Journal, 160, 464-470.

http://dx.doi.org/10.1016/j.ahj.2010.06.012

[41] Sartori, S., Nielsen, I., Tassinari, D., Maestri, A. and Abbasciano, V. (1991) Intracellular Magnesium Concentrations and Acute Anthracycline-Induced Cardiotoxicity. British Journal of Cancer, 64, 785-787. http://dx.doi.org/10.1038/bjc.1991.399

[42] Šimůnek, T., Štěrba, M., Holečková, M., et al. (2005) Myocardial Content of Selected Elements in Experimental Anthracycline-Induced Cardiomyopathy in Rabbits. Biometals, 18, 163-169. http://dx.doi.org/10.1007/s10534-004-4491-7

[43] Alhosaini, M. and Leehey, D.J. (2015) Magnesium and Dialysis: The Neglected Cation. American Journal of Kidney Diseases, 66, 523-531.

http://dx.doi.org/10.1053/j.ajkd.2015.01.029

[44] Yan, L., Zhu, T., Sun, T., et al. (2010) Activation of Calcium-Sensing Receptors Is Associated with Apoptosis in a Model of Simulated Cardiomyocytes Ischemia/Reperfusion. Journal of Biomedical Research, 24, 301-307. http://dx.doi.org/10.1016/S1674-8301(10)60042-5

[45] Sossalla, S., Wagner, S., Rasenack, E.C., et al. (2008) Ranolazine Improves Diastolic Dysfunction in Isolated Myocardium from Failing Human Hearts-Role of Late Sodium Current and Intracellular Ion Accumulation. Journal of Molecular and Cellular Cardiology, 45, 32-43. http://dx.doi.org/10.1016/j.yjmcc.2008.03.006

[46] Kaufmann, S.G., Westenbroek, R.E., Maass, A.H., et al. (2013) Distribution and Function of Sodium Channel Subtypes in Human Atrial Myocardium. Journal of Molecular and Cellular Cardiology, 61, 133-141. http://dx.doi.org/10.1016/j.yjmcc.2013.05.006

[47] Nair, P. and Nair, R.R. (2000) Alteration in Cardiomyocyte Mechanics by Suboptimal Levels of Extracellular Magnesium. Biological Trace Element Research, 73, 193-200. http://dx.doi.org/10.1385/BTER:73:3:193

[48] Imlay, J.A. (2014) The Mismetallation of Enzymes during Oxidative Stress. Journal of Biological Chemistry, 289, 28121-28128. http://dx.doi.org/10.1074/jbc.R114.588814

[49] Brissot, P., Ropert, M., Le Lan, C. and Loréal, O. (2012) Non-Transferrin Bound Iron: A Key Role in Iron Overload and Iron Toxicity. Biochimica et Biophysica Acta, 1820, 403410. http://dx.doi.org/10.1016/j.bbagen.2011.07.014

[50] Gammella, E., Recalcati, S., Rybinska, I., Buratti, P. and Cairo, G. (2015) Iron-Induced Damage in Cardiomyopathy: Oxidative-Dependent and Independent Mechanisms. Oxidative Medicine and Cellular Longevity, 2015, Article ID: 230182. http://dx.doi.org/10.1155/2015/230182

[51] Ferrans, V.J., Clark, J.R., Zhang, J., Yu, Z.X. and Herman, E.H. (1996) Pathogenesis and 
Prevention of Doxorubicin Cardiomyopathy. Tsitologiia, 39, 928-937.

[52] Jones, R.L., Swanton, C. and Ewer, M.S. (2006) Anthracycline Cardiotoxicity. Expert Opinion on Drug Safety, 5, 791-809. http://dx.doi.org/10.1517/14740338.5.6.791

[53] Ichikawa, Y., Ghanefar, M., Bayeva, M., et al. (2014) Cardiotoxicity of Doxorubicin Is Mediated through Mitochondrial Iron Accumulation. The Journal of Clinical Investigation, 124, 617-630. http://dx.doi.org/10.1172/JCI72931

[54] Ferreira-Machado, S.C., Salata, C., Rocha, N.N., et al. (2013) Caspase-3 Activation and Increased Procollagen Type I in Irradiated Hearts. Anais da Academia Brasileira de Ciências, 85, 215-222. http://dx.doi.org/10.1590/S0001-37652013005000009

[55] Vadakkumpadan, F., Arevalo, H., Prassl, A.J., Chen, J., Kickinger, F., Kohl, P., Trayanova, N., et al. (2010) Image-Based Models of Cardiac Structure in Health and Disease. Wiley Interdisciplinary Reviews. Systems Biology and Medicine, 2, 489-506. http://dx.doi.org/10.1002/wsbm.76

[56] Alizadeh, A.M., Faghihi, M., Khori, V., et al. (2012) Oxytocin Protects Cardiomyocytes from Apoptosis Induced by Ischemia-Reperfusion in Rat Heart: Role of Mitochondrial ATP-Dependent Potassium Channel and Permeability Transition Pore. Peptides, 36, 71-77. http://dx.doi.org/10.1016/j.peptides.2012.03.023

Submit or recommend next manuscript to SCIRP and we will provide best service for you:

Accepting pre-submission inquiries through Email, Facebook, LinkedIn, Twitter, etc.

A wide selection of journals (inclusive of 9 subjects, more than 200 journals)

Providing 24-hour high-quality service

User-friendly online submission system

Fair and swift peer-review system

Efficient typesetting and proofreading procedure

Display of the result of downloads and visits, as well as the number of cited articles

Maximum dissemination of your research work

Submit your manuscript at: http://papersubmission.scirp.org/

Or contact ajac@scirp.org 